\title{
Considerations on Direct Antiviral Agent Therapy in Patients Having Chronic Hepatitis C from Constanta County
}

\author{
Stavar Angelica1', Dumitru Irina-Magdalena², Rugina S² \\ Constanta County Hospital, Clinic of Internal Medicine \\ ${ }^{2}$ Faculty of Medicine, Constanta
}

\begin{abstract}
Introduction: Direct-acting antiviral agents (DAA) have a direct action in chronic hepatitis C, their addition to the standard therapy with interferon alfa2 (IFN) and ribavirin (RBV) significantly improving the sustained virologic response (SVR) in this disease.

Objective: The study analyses the results of triple therapy inclduign DAA in terms of tolerability and efficiency.

Material and method: We selected a lot of 24 patients who concluded the DAA administration period, being in the period of finalization of standard therapy at the time of the study. In all the patients clinical and paraclinical assesment was performed including laboratory tests, fibroscan, echography, etc.

Results: The duration of the therapy consisting in association of DAA to the standard treatment was 3 months and led to a remarkable result represented by a high rate of negativation of viremia (83.3\%). Among the adverse reactions recorded, the most important were: anemia 17 patients (70.8\%), leucopenia 10 patients (41.6\%), thrombocitopenia 14 patients (58.3\%), hyperbilirubinemia 3 patients (12,5\%); hyperuricemia 8 patients (33,3\%), hypocalcemia 4 patients (16.6\%), loss of weight 4 patients (16,6\%), anal pruritus (16,6\%); among the 24 patients, $2 \%$ did not exhibit any adverse reactions.

Conclusions: Despite of the various adverse reactions recorded, the triple therapy consisting in DAA added to the standard treatment proves its utility, and the high rates of sustained viral reaction justifies its utilization. It is necessary to increase the number of patients who benefit from the advantages of triple therapy, which, after becoming larger available, could become a new standard therapy in patients with viral chronic hepatitis.
\end{abstract}

Keywords: direct-acting antiviral agents, Hepatitis C virus, sustained virologic response

Received: 14 September 2014 / Accepted: 23 October 2014

\section{Introduction}

More than 180 million people worldwide are infected with the chronic hepatitis $\mathrm{C}$ virus (HCV), a major cause of liver cirrhosis, whose life-threatening complications include liver failure, portal hypertension and hepatocellular carcinoma [1]. In patients infected with HCV genotype 1, the chances of a sustained virologic response (SVR) with the previous standard of care treatment (Peg-IFN- $\alpha+$ ribavirin) are only $40-50 \%$. Triple therapy, with DAA in combination with Peg-IFN- $\alpha$ + ribavirin, is the new standard of care for chronic hepatitis $\mathrm{C}$ treatment in genotype 1-infected patients [2].

Two NS3-4A protease inhibitors (boceprevir and telaprevir) are highly potent and were approved in Europe and in the United States in 2011 in combination with pegylated interferon (IFN)- $\alpha$ and ribavirin for the treatment of chronic hepatitis $\mathrm{C}$ related to HCV genotype 1 [3].

Treatment with available direct-acting antiviral (DAA) drugs has increased sustained virologic response (SVR) rates in genotype 1 infection and shortened duration of therapy in many patients, but these agents have a low barrier to resistance. Initial monoterapy studies of these

Correspondence to: Angelica Stavar

E-mail: angel.stavar@yahoo.com agents showed prompt suppression of viral activity and rapid emergence of resistance, requiring that they could be administered along with a interferon alfa and ribavirin to prevent resistance, 12 weeks and 24 weeks after stopping DAA treatment [3-4].

\section{Objective}

The study analyses the effect of triple therapy including DAA (Telaprevir for 12 weeks) in terms of tolerability and efficiency.

\section{Material and method}

A lot of 24 patients was included in the study, who have concluded the DAA administration period, being in the period of finalization of standard therapy at the time of the study. The study was conducted in accordance to the declaration of Helsinki.

\section{Inclusion Criteria}

- Patients with HCV infection, 18 years to 70 years.

- Patients with HCV infection, with F3-F4 fibrosis evaluated by liver biopsy or non-invasive staging assessments such as FibroScan, MR-Elastography, or FibroTest/FibroSure.

- Patient must have had a liver biopsy before screening 
(or between the screening and baseline visit), unless they had a contraindication for procedure or any evidence of portal hypertension not associated with cirrhosis. For patients who had a liver biopsy performed more than 2 years prior to screening or without a biopsy (in case of a contraindication or portal hypertension), a non-invasive staging assessment was required, such as FibroScan, MRElastography, or FibroTest/FibroSure, which should have not been older than 6 months prior to screening.

- Chronicity of hepatitis $\mathrm{C}$ virus (HCV) infection, as confirmed by one or both of the following: presence of anti$\mathrm{HCV}$ antibody and/or HCV ribonucleic acid (RNA) at least 6 months prior to the screening visit and/or presence of fibrosis on biopsy.

- Genotype $1 \mathrm{HCV}$ infection with plasma HCV RNA of $>10,000 \mathrm{IU} / \mathrm{mL}$ (both confirmed at screening).

- Partial and Null Responders patients at previous treatment with PegINF PegINF $\alpha-2 a$ or PegINF $\alpha-2 b$ in combination with ribavirin (RBV).

- Patient must have had at least 1 documented previous course of treatment with PegINF $\alpha-2 a$ or PegINF $\alpha-2 b$ in combination with ribavirin (RBV) (at least 12 weeks for null responder and 20 weeks for partial responder).

- Patients (male and female) will use double barrier of contraception, condoms and cervical capeline.

\section{Exclusion Criteria}

- Hepatic decompensation (impaired functioning of the liver), as indicated by significant laboratory abnormalities or other active diseases.

- No hepatoarconoma or other malignancies.

- Infection with Human Immunodeficiency Virus (HIV) or non genotype 1 hepatitis $C$.

- Liver disease not related to hepatitis C infection.

- Previous chronic hepatitis $\mathrm{C}$ treatment, other than PegIFN and RBV.

- Pregnancy or breastfeeding.

The patients were evaluated at screening visit in clinical (physical examinations) and paraclinical terms: laboratory tests (HLG, biochemical analysis, urine collection, virus C genotype), liver biopsy or fibroscan, echography, electrocardiogram.

Study assessments at each study visit $(1,2,4,6,8,12$ weeks) included: blood (HLG, ALT, AST, BT, BD, lipid profile, uric acid, electrolytes) and urine collection for testing, electrocardiogram (ECG) assessments, physical examinations and pregnancy test for females.

\section{Results}

We enrolled 24 patients (16 male and 8 female, aged between 32-64 years, median age 48 years), known to have chronic hepatitis $\mathrm{C}$, out of which 6 patients null responder and 18 partial responder, with F3-F4 fibrosis by METAVIR score (Table 1).
Table 1. Baseline characteristics

\begin{tabular}{lll}
\hline Gender & M/F & $16 / 8$ \\
\hline Age & $32-64$ years & $\begin{array}{l}\text { Median } 48 \\
\text { years }\end{array}$ \\
$\begin{array}{l}\text { Response to previous } \\
\text { treatment with PegIFN and }\end{array}$ & $\begin{array}{l}\text { null responder/ } \\
\text { partial responder }\end{array}$ & $6 / 18$ \\
Fibrosis by METAVIR score & F3/F4 & $13 / 11$ \\
\hline
\end{tabular}

The duration of the therapy association with DAA (Telaprevir $2250 \mathrm{mg} /$ day, $750 \mathrm{mg}$ at every 8 hours after eating) to the standard treatment was 3 months, with remarkable virulogical results meaning that after the utilization of the triple therapy a high rate of undetectable viremia was recorded at W12 in $83.3 \%$ of patients, while only two patients had detectable viremia at W12.

Tolerability was variable. Among the adverse reactions recorded, most frequent were: anemia 17 patients (70.8\%), leucopenia, 10 patients (41.6\%), thrombocitopenia 14 patients $(58.3 \%)$, hyperbilirubinemia 3 patients $(12,5 \%)$; hyperuricemia 8 patients $(33,3 \%)$, hypocalcemia 4 patients (16.6\%), loss of weight 4 patients $(16,6 \%)$, anal pruritus $(16,6 \%)$; only $2 \%$ of patients did not present any remarkable adverse reactions (Fig. 1, Table 2).

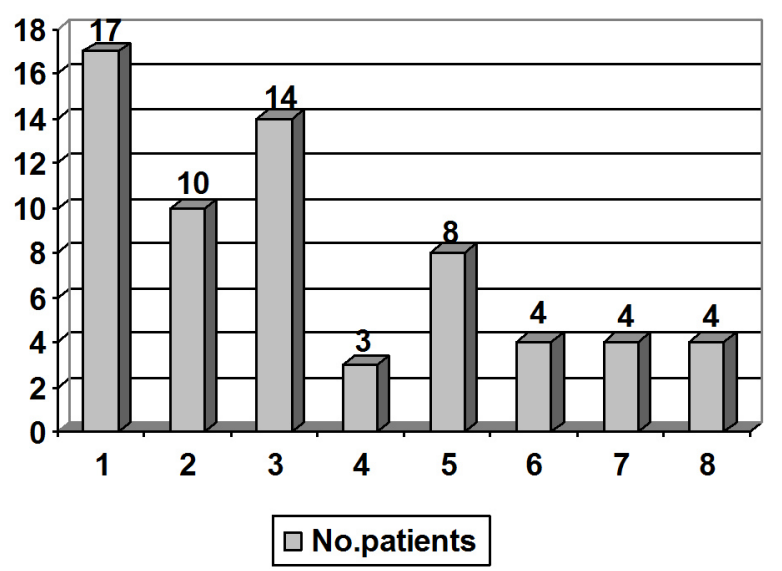

Fig.1 Adverse reactions

The laboratory results recorded in the study population are presented in table 3 .

In cases with severe anemia the dose of ribavirin was reduced to $600 \mathrm{mg} /$ day, without interruption of Telaprevir treatment. No serious adverse events requiring discontinuation of therapy were reported.

\section{Discussion}

The standard of care for treatment of HCV genotype 1 changed since the approval of two new DAA drugs (telaprevir and boceprevir) for use in pegylated interferonbased and ribavirin-based triple therapy in 2011 [5]. Until 2011, the standard therapy with pegylated interferon and ribavirin produced an SVR rate of approximately 40-50\% for genotype 1 after 24-48 weeks of therapy [6]. Experience has shown improved response rates and treatment 
Table 2. Adverse reactions

\begin{tabular}{|c|c|c|c|c|}
\hline Legend & Adverse reaction & Mild & Medium & Severe \\
\hline 1 & anemia & 5 patients $(20.8 \%)$ & 8 patients $(47 \%)$ & 4 patients $(24 \%)$ \\
\hline 2 & leucopenia & 7 patients (70\%) & 3 patients (30\%) & 0 \\
\hline 3 & thrombocitopenia & 9 patients $(64 \%)$ & 5 patients $(36 \%)$ & 0 \\
\hline 4 & hyperbilirubinemia & 3 patients $(12,5 \%)$ & 0 & 0 \\
\hline 5 & hyperuricemia & 3 patients (38\%) & 0 & 5 patients, $(63 \%)$ \\
\hline 6 & hypocalcemia & 2 patients (50\%) & 0 & 2 patients $(50 \%)$ \\
\hline 7 & loss of weight & 4 patients $(16,6 \%)$ & 0 & 0 \\
\hline 8 & anal pruritus & 4 patients $(16,6 \%)$ & 0 & 0 \\
\hline
\end{tabular}

Table 3 - Laboratory results in the study population

\begin{tabular}{|c|c|c|c|c|}
\hline Parameter & Adverse reaction & Mild & Medium & Severe \\
\hline $\mathrm{Hgb}$ & anemia & $10.0-10.9 \mathrm{~g} / \mathrm{dl}$ & $9.99-9.9 \mathrm{~g} / \mathrm{dl}$ & $7.0-8.9 \mathrm{~g} / \mathrm{dl}$ \\
\hline WBC & leucopenia & $2.000-2500 / \mathrm{mm}^{3}$ & $1500-1999 / \mathrm{mm} 3$ & $1000-1499 / \mathrm{mm} 3$ \\
\hline Platelets & thrombocitopenia & $100.000-124999 / / \mathrm{mm}^{3}$ & $50.000-99999 / \mathrm{mm}^{3}$ & $25000-49999 / \mathrm{mm}^{3}$ \\
\hline Total bilirubin & hyperbilirubinemia & $>/=1.1$ to $</=1.5 x$ ULN & $>/=2.5$ to $</=5.00 \times$ ULN & $>5.00 \times$ ULN \\
\hline Uric acid & hyperuricemia & $7.5-10.0 \mathrm{mg} / \mathrm{dl}$ & $7.0-7.7 \mathrm{mg} / \mathrm{dl}$ & $12.1-15.0 \mathrm{mg} / \mathrm{dl}$ \\
\hline Calcium serum & hypocalcemia & $7.8-8.4 \mathrm{mg} / \mathrm{dl}$ & $7.8-8.4 \mathrm{mg} / \mathrm{dl}$ & $6.1-6.9 \mathrm{mg} / \mathrm{dl}$ \\
\hline Body weight & loss of weight & $\begin{array}{c}5-9 \% \text { loss in body weight from } \\
\text { baseline }\end{array}$ & $\begin{array}{c}10-19 \% \text { loss in body weight from } \\
\text { baseline }\end{array}$ & $\begin{array}{l}>19 \% \text { loss in body weight } \\
\text { from baseline }\end{array}$ \\
\hline
\end{tabular}

durations for many patients with genotype $1 \mathrm{HCV}$ infection after DAA treatment, with SVR rates as high as $63-75 \%$ and reduction in duration of therapy by half for many patients. Telaprevir efficacy was initially proven in multiple large multicenter trials [7-10]. As in our study, viral response after 12 weeks of triple therapy was $70-80 \%$ in prior null responders or partial responders.

In all clinical trials, the most common drug reactions to Telaprevir were rash, pruritus, anemia, nausea, hemorrhoids, diarrhea, anorectal discomforte, dysgeusia (alteration of taste), fatigue, vomiting and anal pruritus [7-10]. Rash developed in $56 \%$ of study subjects and severe rash was reported in $4 \%$ of subjects who received Telaprevir combination therapy [7-10]. In our study, no patient presented any form of rash.

Regarding anemia, clinical trials reported that $36 \%$ of patients had hemoglobin values less than or equal to 10 $\mathrm{g} / \mathrm{dL}$ while hemoglobin values less than $8.5 \mathrm{~g} / \mathrm{dL}$ were reported in $14 \%$ of them, similar to observations in our study.

Anorectal events were reported in $29 \%$ of subjects treated with Telaprevir combination treatment. The majority of these anorectal events included hemorrhoids, anorectal discomfort, anal pruritus and rectal burning which were mild to moderate in severity [7-10]. In our study 4 patients $(16,6 \%)$ had only anal pruritus which disappeared after the end of therapy.

\section{Conclusions}

Chronic HCV infection is a public health problem on both global and national level, predominantly affecting middle-age, socially and professionally active people. It requires involvement of specialists in the sense of a permanent optimization of therapy to maintain a well-balanced cost/efficiency. The triple therapy, with DAA added to the standard therapy, proves its utility despite the various adverse reactions recorded, the high rates of sustained viral reaction justifying its utilization.

Anemia is the most common adverse reaction and the patients in our study had the highest proportion of moderate form of anemia. Leucopenia was observed in the study in approximately $40 \%$ of patients, being predominantly mild and without notable implications on therapy.

Thrombocytopenia was present in $50 \%$ of patients, predominantly mild form which did not require any adjustment in the interferon dose.

\section{References}

1. Jazwinski A B, Muir AJ. Direct-Acting Antiviral Medications for Chronic Hepatitis C Virus Infection. Gastroenterol Hepatol (N Y). 2011;7(3):154162.

2. Kai TS. Expert Opinion. Pharmacotherapy. 2012;13(4):593-606

3. Pawlotsky JM. Treatment of chronic hepatitis C: current and future. Curr top microbiol immunol. 2013;369:321-42.

4. Welsch C, Jesudian A, Zeuzem S, Jacobson I. New direct-acting antiviral agents for the treatment of hepatitis $C$ virus infection and perspectives. Gut. 2012;61 Suppl 1:i36-46.

5. Casey LC, Lee W M. Hepatitis C Virus Therapy Update 2013. Curr Opin Gastroenterol. 2013;29(3):243-249.

6. Ghany M, Nelson D, Strader D, et al. AASLD Practice Guideline. An update on treatment of genotype 1 chronic hepatitis $C$ virus infection: 2011 practice guideline by the American Association for the Study of Liver Disease. Hepatology 2011; 54:1433-1444.

7. McHutchison J, Everson G, Gordon C, et al. Telaprevir with peginterferon and ribavirin for chronic HCV genotype 1 infection. $\mathrm{N}$ Engl $\mathrm{J}$ Med 2009;360:1827-1838.

8. Hezode C, Forestier N, Dusheiko G, et al. Telaprevir and peginterferon with or without ribavirin for chronic HCV infection. N Engl J Med 2009; 360:1839-1850.

9. Jacobson I, McHutchison J, Dusheiko G, et al. Telaprevir for previously untreated chronic hepatitis C virus infection. N Engl J Med 2011;364:24052416.

10. Zeuzem S, Andreone P, Pol S, et al. Telaprevir for retreatment of HCV infection. N Engl J Med 2011;364:2417-2428. 